\title{
EXPERIMENTAL SILANE PRIMER AND GRIT-BLASTING DISTANCE IN ORTHODONTIC BONDING OF ZIRCONIA SURFACES
}

\author{
"BANGALORE H. DURGESH*, SAMER M. ALAQEEL*, NANCY AJWA**, MAJDAH ALKHADHARI***, \\ OMAR ALSADON*, ****, JUKKA P. MATINLINNA***** \\ *Dental Health Department, College of Applied Medical Sciences, King Saud University \\ P.O. Box 10219, Riyadh 11433, Saudi Arabia \\ **Preventive Dentistry Department, Riyadh Elm University, Riyadh 13244, Kingdom of Saudi Arabia \\ ***Department of Restorative Dentistry, King Abdulaziz Medical City, Jeddah 21423, Saudi Arabia \\ ****Engineer Abdullah Bugshan Research Chair for Dental and Oral Rehabilitation, College of Dentistry, \\ King Saud University, Riyadh, Saudi Arabia \\ *****Dental Materials Science, Applied Oral Sciences and Community Dental Care, Faculty of Dentistry, \\ The University of Hong Kong, Hong Kong SAR, PR China \\ \#E-mail: drdurgesh19@gmail.com
}

Submitted June 26, 2020; accepted September 24, 2020

\begin{abstract}
Keywords: Zirconia, Grit-blasting, Adhesion strength, Silane primers, Wettability
The objective of this study is to evaluate the effect of an experimental adhesive silane blend system in achieving optimal orthodontic bonding to zirconia surfaces. Also, the effect of the sandblasting distance on the adhesion strength and surface roughness of the zirconia bonding surface was determined. A total of 180 zirconia specimens were used for 3 test groups $(n=60)$, and then grit-blasted with various distance $(5 \mathrm{~mm}, 10 \mathrm{~mm}$ and $15 \mathrm{~mm})$. The grit-blasted specimens were allocated to three silanizations $(n=30)$ : with $1.0 \mathrm{vol} . \% 3$ methacryloyloxypropyltrimethoxy-silane (EP1) or their blends with $0.5 \%$ (EP2), and 1.0 vol. \% (EP3) 1, 2-bis-(triethoxysilyl) ethane (all in ethanol/water). Premolar brackets were bonded to zirconia specimen surfaces using Transbond ${ }^{\mathrm{TM}} X T$ adhesive resin. Next, ten specimens from each subgroup were subjected to thermo-cycling of 5000 cycles. Adhesion strength tests were performed at baseline (dry), and after thermo-cycling. The grit-blasted specimens were studied by scanning electron microscopy (SEM) and their surface roughness was evaluated. Contact angles and wettability of the primers on the zirconia surface was determined. The highest surface roughness was $0.69 \pm 0.0097 \mu \mathrm{m}$ for specimens grit-blasted at a distance of $5 \mathrm{~mm}$ (group 1), and the lowest surface roughness was $0.29 \pm 0.0078 \mu \mathrm{m}$ for the control specimens. Significant differences in the mean surface roughness were observed between the study groups $(P<0.05)$. ANOVA showed a significant influence of the grit-blasting distance, silane blend and artificial aging on the shear bond strength values $(P<0.05)$. The highest adhesion strengths were obtained for baseline specimens irrespective of the grit-blasting distance or the silane primer blend system used. The water contact angle of the control zirconia specimen was $53.5^{\circ}$ and the contact angle ranged between $3-7^{\circ}$ after primer coating. Grit-blasting at $10 \mathrm{~mm}$ and silane primer blend system of 1.0 vol\% 3-methacryloyloxy-propyltrimethoxysilane +0.5 vol. \% 1,2-bis- (triethoxysilyl) ethane demonstrated optimal orthodontic bonding with least surface damage to the zirconia surface.
\end{abstract}

\section{INTRODUCTION}

The number of adults seeking orthodontic treatment has tremendously increased during the last two decades. This said, the orthodontist is often challenged to bond orthodontic attachments to a variety of restorative surfaces including those containing porcelain material [1]. In recent years, zirconium dioxide $\left(\mathrm{ZrO}_{2}\right)$ or zirconia is the commonly used restorative biomaterial for orthodontic bonding. That is due to its exceptional mechanical properties such as high flexural and compressive strengths, relatively low modulus of elasticity, and good biocompatibility $[2,3]$. The biomedical grade zirconia usually contains 3 mol. \% yttria $\left(\mathrm{Y}_{2} \mathrm{O}_{3}\right)$ as a stabilizer, which accordingly enhances its mechanical properties [4].
On the contrary, the exceptionally inert behavior of zirconia results in a weak bonding to the resin cement. A previous study on the bond strength between untreated zirconia surface and resin composite have demonstrated a shear bond strength of $1.5 \mathrm{MPa}$, which is very low compared to the acceptable bond strength value of $5 \mathrm{MPa}$ [5]. Hence, surface treatment of the zirconia is recommended. Surface roughness of the bonding surface is one of the important factors determining the success of mechanical retention of resin to the surface. The same concept also applies to orthodontic bonding, where the orthodontic brackets are retained on to the tooth or the restorative surfaces by micro-mechanical retention. Rough surfaces allow free flow of resin composites into the surface, thereby forming an irregular surface 
on the bonding substrate and accordingly enhancing the adhesion strength [6]. However, an over exaggerated surface roughness might pose a risk for the bonding surface, thereby compromising its mechanical properties.

Surface conditioning of silica based ceramics is routinely performed using phosphoric acid $\left(\mathrm{H}_{3} \mathrm{PO}_{4}\right)$ or hydrofluoric acid (HF). However, non-silica based zirconia ceramics are resistant to acid-etching due to the absence of the glassy phase. Furthermore, the lack of silica also impedes chemical bonding between silicasilane necessary for silanization. Previous studies have demonstrated that grit-blasting is an effective technique for surface roughening with least damage to surface [7, 8]. Grit-blasting with alumina particles creates high surface energy, and in principle promotes micro-mechanical retention [9]. Therefore, it has been hypothesized that zirconia surface pretreatment by physico-chemical methods involving combination of airborne-particle abrasion and adhesion promoters such as silane primers, might enhance the bond strength [10].

Silanes promote adhesion between the hydrophobic resin composite and the hydrophilic silica-coated surfaces. The application of silane lowers the surface tension of a substrate, wet it and increases its surface energy, thus paving the way for effective bonding [9]. Organofunctional silanes are made of two different reactive functional groups that can react and blend with various organic and inorganic materials. Thus, they promote and increase adhesion between dissimilar materials. The functional hydrolysable groups react with the surface hydroxyl groups of inorganic substrates, while the organic functional groups react with the functional groups of the resins [3]. The addition of cross-linking silane to a functional silane has demonstrated enhanced bonding and hydrolytic stability of the interfacial siloxane layer between zirconia and the resin composite $[9,11,12]$.<smiles>C=C(C)C(=O)OCCC[Si](OC)(OC)OC</smiles>

3-methacryloxypropyltrimethoxysilane<smiles>CO[Si](CC[Si](OC)(OC)OC)(OC)OC</smiles>

bis-1,2-(triethoxysilyl)ethane

Figure 1. Chemical structure of the experimental primers.
The aim of this study was, therefore, to evaluate the effect of an experimental adhesive silane blend system containing 3-methacryloyloxypropyltrimethoxysilane (MPS) (organo-functional silanes) or their blends with 1, 2-bis- (triethoxysilyl) ethane (BTSE) (cross-functional silane) in achieving optimal orthodontic bonding to zirconia surfaces. Also, the effect of the grit-blasting distances on the adhesion strength and surface roughness of the zirconia bonding surface was studied.

\section{EXPERIMENTAL}

Experimental silane primer preparation

The preparation of experimental silane primer was in accordance with a previous published study [11, 12]. Chemical formulas of the experimental primers are presented in Figure 1.

Three experimental silane primers were prepared using 1 vol. \% organofunctional silane monomer, 3-methacryloxypropyltrimethoxysilane (MPS) with 0.5 vol. $\%$, and 1 vol. $\%$ of cross-linking silane 1,2 -bis(triethoxysilyl) ethane (BTSE) in 95\%: $5 \%$ ethanolwater (used as such without redistillation). The $\mathrm{pH}$ of the primer solution was adjusted to 4.1, and was activated by hydrolysis for $23 \mathrm{~h}$ at room temperature. All the primers were kept in dark until use. Accordingly, the 3 sets of experimental primers (EP) after mixing are as follows:

$$
\begin{aligned}
& \text { EP1 - } 1.0 \text { vol. \% MPS + } 0 \text { vol. \% BTSE } \\
& \text { EP2 - } 1.0 \text { vol. \% MPS + } 0.5 \text { vol. \% BTSE } \\
& \text { EP3 - } 1.0 \text { vol. \% MPS + } 1.0 \text { vol. \% BTSE }
\end{aligned}
$$

\section{Zirconia specimen preparation}

A total of 180 zirconia specimens $(6.0 \times 6.0 \times 4 \mathrm{~mm}$ thick) were obtained from densely sintered, yttriumstabilized HIP (hot isostatic pressing) zirconia blanks. The blanks were sectioned with a diamond saw, and the obtained specimens were polished using 600-grit silicon carbide paper. The zirconia specimens were individually embedded in self-cure resin (Orthoresin, DeguDent $\mathrm{GmbH}$, Hanau, Germany). Following polymerization, the specimens were randomly allocated to three $(n=60)$ groups. In group 1: the specimens were grit-blasted using alumina powder $(110 \mu \mathrm{m}, 2.5 \mathrm{bar}, 4 \mathrm{~s})$ from a distance of approximately $5 \mathrm{~mm}$ by a hand device (LEMAT NT4, Wassermann, Hamburg, Germany) held perpendicular to the zirconia surface. In group 2 and group 3, the same protocol of grit-blasting was followed except that the distance of the hand device from the zirconia surface was $10 \mathrm{~mm}$ and $15 \mathrm{~mm}$ respectively. Subsequently, all the specimens were cleansed in an ultrasonic unit for ten minutes. The grit-blasting setup is illustrated in Figure 2a. 


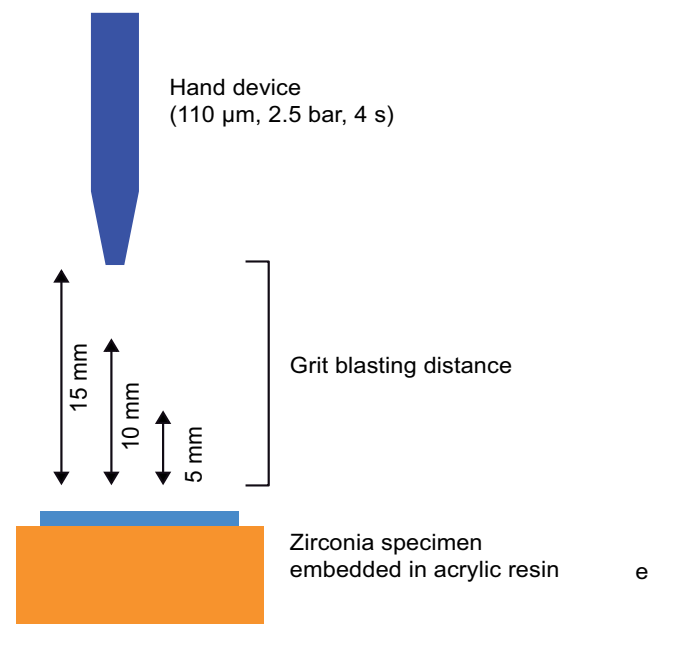

a)

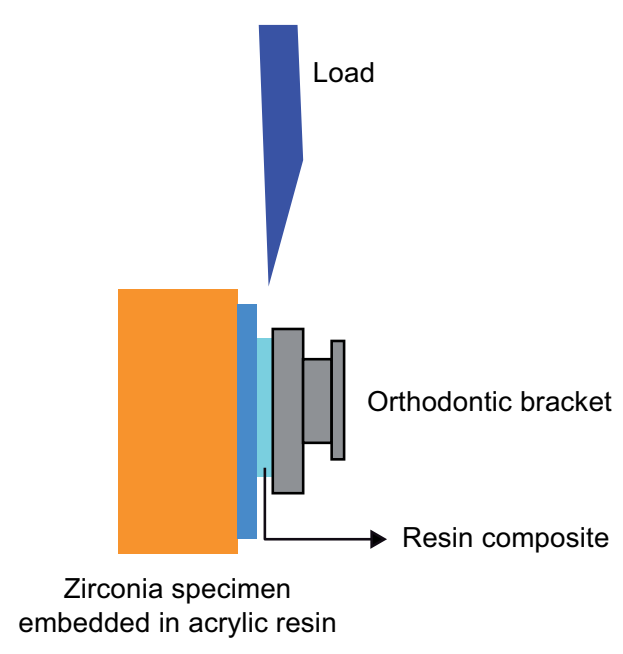

b)

Figure 2. Grit-blasting setup (a) and adhesion strength test setup (b).

\section{Surface roughness assessment}

The surface roughness $\left(R_{a}\right)$ of the zirconia specimens before and after surface treatment was evaluated using a non-contact profilometer (Bruker Contour GT, Tucson, AZ, USA). The nanolens atomic force microscopy (AFM) module of the profilometer device and a fully automated turret with programmable three directional $(\mathrm{X}, \mathrm{Y}, \mathrm{Z})$ movements provides high resolution data of the scanned surface. Three specimens in each group were included for roughness assessment, and each specimen was scanned at five different areas to obtain the mean value of that particular specimen.

\section{Scanning Electron Microscopy (SEM)}

The surface topographic changes following surface treatment of the representative specimen in each study group were evaluated using SEM (JEOL JSM-5900 LV SEM, Tokyo, Japan). The scanning electron microscope was operated at $20 \mathrm{kV}$, in vacuum and with a $1000 \times$ magnification.

\section{Primer application and orthodontic bonding}

Each group was further divided into 3 subgroups ( $n=20)$ according to the primer used. Thus there were 9 study groups ( 3 grit-blasting distances with 3 primers).

Group 1a: in this group, a thin single coat of an experimental silane primer (EP1) was applied with a fine disposable brush onto the grit-blasted zirconia surface and allowed to dry for $30 \mathrm{~s}$.

Group 1b: a thin single coat of an experimental silane primer (EP2) was applied as explained above.

Group 1c: a thin single coat of an experimental silane primer (EP3) was applied as explained above.
The primer application of specimens for the subgroups of group 2 (a-c) and group 3 (a-c) was similar to that of the respective subgroups (a-c) of group 1 . Following primer application, orthodontic bonding was performed. For this purpose, premolar metal orthodontic brackets (Lancer Orthodontics, Milano, Italy) with a mesh area of $11.4 \mathrm{~mm}^{2}$ were used. The adhesive resin (Transbond ${ }^{\mathrm{TM}} \mathrm{XT}$ ) was applied to the bracket base using a syringe tip, and the bracket was then positioned in the center and pressed firmly on to the zirconia bonding surface. The excess resin composite around the bracket was carefully removed with a sharp scaler before polymerization. The medial and distal surfaces of the bracket edges were light-cured for $20 \mathrm{~s}$ using a hand held light curing unit (Elipar Free Light 2, 3M ESPE, Seefeld, Germany) with a wavelength maximum between $420-540 \mathrm{~nm}$ and a output power of $1505 \mathrm{~mW} \cdot \mathrm{cm}^{-2}$. The light output was monitored using Managing Accurate Resin Curing, MARC, System (Blue Light Analytics, Halifax, Canada). The materials used in the study are presented in Table 1.

\section{Adhesion strength test}

After bonding, all the specimens were stored in distilled water at $37{ }^{\circ} \mathrm{C}$ for $24 \mathrm{~h}$. Ten specimens from each group were tested for adhesion strength (baseline or dry values), and the remaining ten specimens were subjected for aging simulation. The adhesion strength test procedure was in accordance with DIN 13990-1/-2 [13] and the specimen allocation was in accordance with the previous study [14]. For adhesion strength test, the specimens were oriented vertically in a custom made jig of a universal testing machine (Instron Corporation, Canton, MA, USA). The chisel shaped rod with a load 
Table 1. Materials used in the study.

\begin{tabular}{lll}
\hline Material & Batch number & Manufacturer \\
\hline 3-Methacryloxypropyltrimethoxysilane (MPS); Purity: >95\% & 2015730 & Dow Corning, Midland, MI, USA \\
1,2-bis-(triethoxysilyl)ethane (BTSE); Purity:100\% & $4 \mathrm{R}-4325$ & Gelest, Tullytown, PA, USA \\
Everest ${ }^{\circ}$ ZH-Blank & $4367 / 2$ & KaVo, Germany \\
Aluminium-oxide particles; Purity: > 95 \% & 1051348 & Bego, Bremen, Germany \\
TransbondTM XT Light cure orthodontic adhesive & FV5XP & 3M Unitek, Monrovia, CA, USA \\
\hline
\end{tabular}

cell of $2.5 \mathrm{kN}$, attached to the test machine was directed towards the adhesive interface at a constant cross-head speed of $0.5 \mathrm{~mm} / \mathrm{min}$ until fracture occurred at the adhesive interface (Figure $2 b$ ). The force $(\mathrm{N})$ required to debond the bracket from zirconia surface was recorded, and the adhesion strengths were calculated and presented in megapascals (MPa).

\section{Aging simulation}

Aging simulation was accomplished through thermo-cycling for 5000 cycles at temperature between $5{ }^{\circ} \mathrm{C}$ and $55^{\circ} \mathrm{C}$, with a dwell time of $20 \mathrm{~s}$ and a transfer time of $10 \mathrm{~s}$ in a thermo-cycler device (Huber 1100, SD Mechatronik GmbH, Germany). The 5000 cycles represented and equaled to an average orthodontic treatment of 2 years [15]. Following aging, the specimens were subjected to adhesion strength tests (thermo-cycled values).

\section{Failure mode analysis}

After debonding, the zirconia surface and the bracket bases were visually inspected and evaluated to determine the site of predominant bond failure using a light stereomicroscope (Nikon SM2-10, Tokyo, Japan) operating at $20 \times$ magnification. The failure modes were classified according to the adhesive remnant index (ARI) [16]. The ARI interpretation of the scores are as below:

Score 0: no adhesive remaining on the zirconia surface.

Score 1: less than $50 \%$ of the adhesive remaining on the zirconia surface.

Score 2: more than $50 \%$ of the adhesive remaining on the zirconia surface.

Score 3: almost all adhesive remaining on the zirconia surface, with distinct impression of the bracket mesh.

\section{Surface wettability and contact angle measurement}

The surface wettability and contact angle measurement of the experimental primers on the zirconia surface was determined using a camera-based optical tensiometer (Theta Lite, Dyne Technology, Staffordshire, UK). For each group, a sessile drop of the respective experimental primer was applied on the flat zirconia surface with a fine disposable brush. The control specimen was devoid of any primer application. A $1.0 \mu \mathrm{l}$ drop of distilled water from the syringe tip connected to the tensiometer was directed towards the zirconia surface located on a lower movable table. The contact angle was measured $30-40 \mathrm{~s}$, once the droplet was visibly stabilized on the zirconia surface. The contact angle was then measured and computed automatically by the device software.

\section{Statistical analysis}

To determine the differences in mean surface roughness amongst the groups, one-way ANOVA followed by Tukey's post-hoc analysis was applied. Kruskal-Wallis and Mann-Whitney post-hoc tests were applied to compare and determine the differences in mean adhesion strength. ARI scores were reported for both baseline and thermo-cycled specimens in each group. All data analysis was performed using the Statistical Package for Social Sciences (SPSS) v 22 (IBM SPSS Inc., Chicago, IL) statistical software. The significance $P$ was set at 0.05 .

\section{RESULT}

Surface roughness

The highest recorded surface roughness was $0.69 \pm$ $\pm 0.0097 \mu \mathrm{m}$ in specimens grit-blasted at $5 \mathrm{~mm}$ (group 1), and the lowest recorded surface roughness was $0.29 \pm$ $\pm 0.0078 \mu \mathrm{m}$ in the control specimens. Significant difference in the mean surface roughness was observed between the study groups $(P<0.05)$ (Figure 3$)$.

\section{Scanning Electron Microscopy \\ (SEM) examination}

SEM images of the zirconia specimen, grit-blasted at varying distances are presented in Figure 4 . The micrographs taken at $1000 \times$ magnification suggests significant changes between the grit-blasted and non-grit blasted zirconia (control, Figure 4a). Among the gritblasted groups, group 1 (5 mm, Figure 4b) specimens showed increased surface flaws compared to group 2 (10 mm, Figure $4 \mathrm{c})$, and group $3(15 \mathrm{~mm}$, Figure $4 \mathrm{~d})$. Grit-blasted specimen at $15 \mathrm{~mm}$ showed decreased 
surface flaws compared to other grit-blasted groups. Overall, the grit-blasting distance did affect the surface of the zirconia specimen.

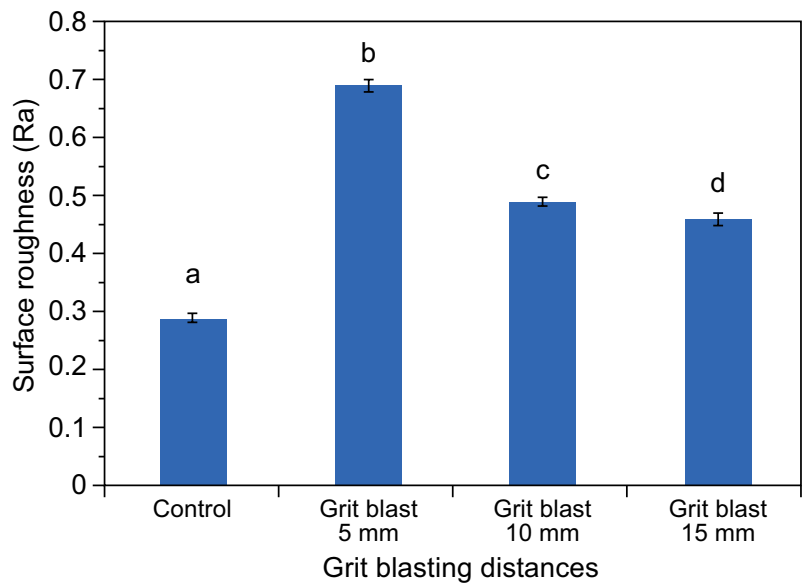

Figure 3. Mean surface roughness (Ra) of the control and grit-blasted zirconia specimens (in $\mu \mathrm{m}$ );

Post-hoc interpretation: Different lower case letter indicates significant differences between the groups.

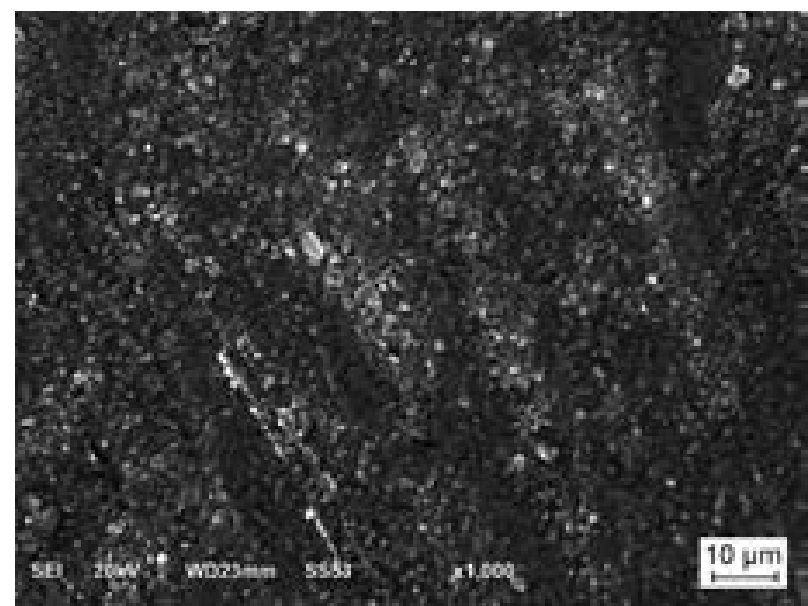

a)

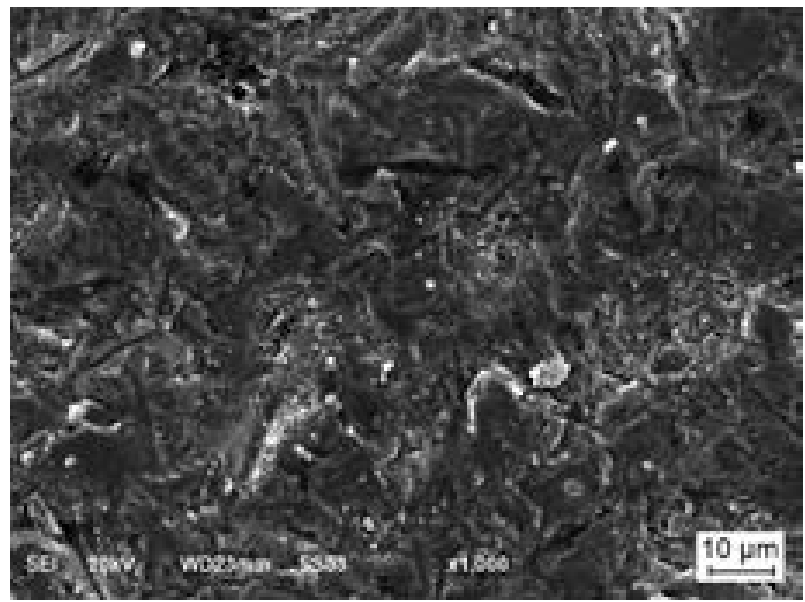

c)
Adhesion strength

The results of the adhesion strength test for the study groups are presented in Table 3. ANOVA showed a significant influence of the grit-blasting distance, silane blend and artificial aging on the shear bond strength values $(P<0.05)$. The highest adhesion strengths were obtained for baseline specimens compared to thermocycled specimens irrespective of the grit-blasting distance or the silane blend.

For the baseline specimens, the highest strength value was seen in group $1 \mathrm{~b}(18.14 \pm 0.57) \mathrm{MPa}$, and the lowest strength was recorded for group $3 c(9.45 \pm 0.45)$ $\mathrm{MPa}$. Among the thermo-cycled specimens, the highest strength value was for group $1 \mathrm{~b}(13.06 \pm 0.91) \mathrm{MPa}$, and the lowest strength was recorded for group $3 \mathrm{a}$ (5.71 \pm 0.46) MPa.

Grit-blasting distances significantly influenced the adhesion strength values $(P<0.05)$. Similarly, there was a significant difference in the adhesion strength values of the baseline (dry) specimens compared to thermo-cycled

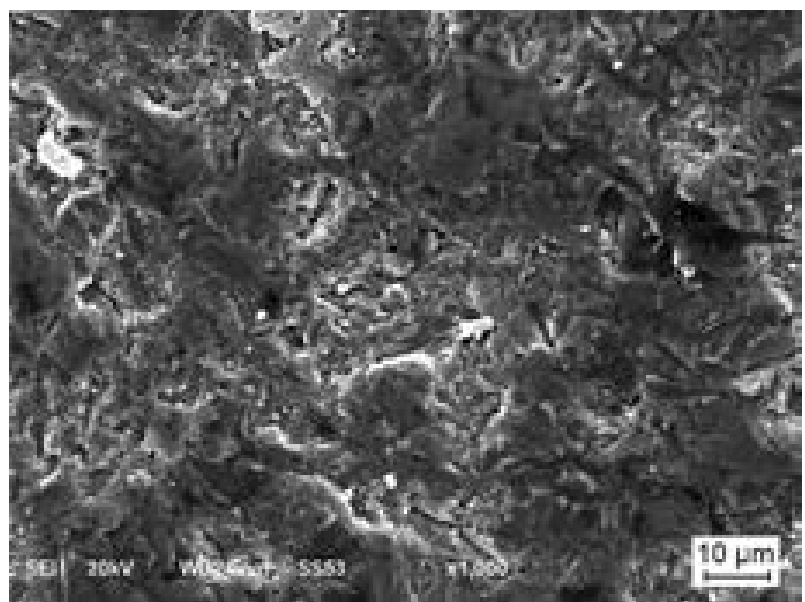

b)

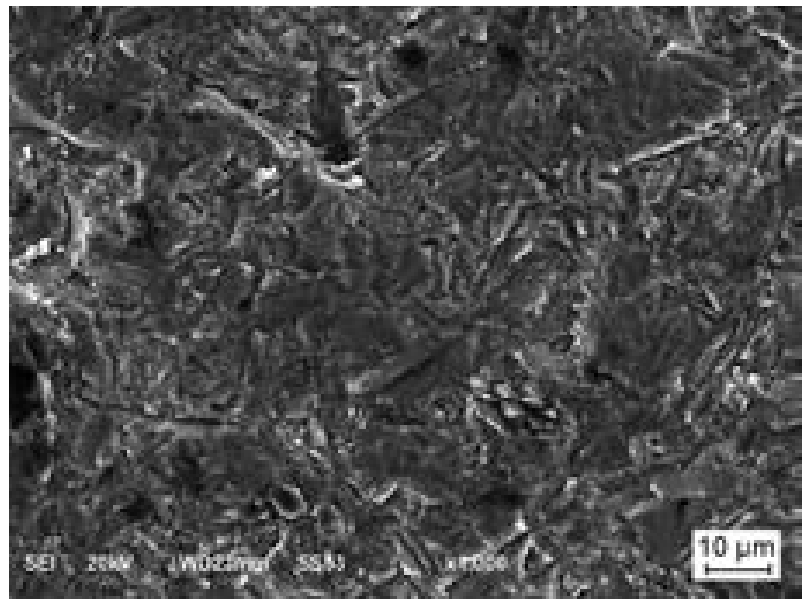

d)

Figure 4. Scanning Electron Microscopy (SEM) micrographs $(1000 \times)$ of the zirconia specimens following grit-blasting at various distances: a) control, b) $5 \mathrm{~mm}$, c) $10 \mathrm{~mm}$, d) $15 \mathrm{~mm}$ ). 
Durgesh B. H., Alaqeel S. M., Ajwa N., Al-Khadari M. A., Alsadon O., Matinlinna J. P.

specimens $(P<0.05)$. The specimens grit-blasted at $5 \mathrm{~mm}$ distances recorded highest adhesion strength values and the lowest values were observed in the specimens gritblasted at $15 \mathrm{~mm}$ distance. Comparing the silane primer or their blend, experimental primer, EP2 (1.0 vol. \% MPS + 0.5 vol. $\%$ BTSE) promoted enhanced adhesion compared to experimental primer EP1 (1.0 vol. \% MPS +0 vol. \% BTSE), and EP3 (1.0 vol. \% MPS + 1.0 vol. \% BTSE) in all the groups. The lowest adhesion strength values were obtained with experimental primer EP3. The increased surface roughness values corresponded well with the high adhesion strength values of the specimens.

Table 2. Adhesion strength (mean (SD)) of the groups.

\begin{tabular}{|c|c|c|}
\hline \multirow{2}{*}{ Groups } & \multicolumn{2}{|c|}{ Adhesion strength (MPa) } \\
\hline & Baseline & $\overline{\text { Artificial aging }}$ \\
\hline \multicolumn{3}{|c|}{ Group 1 (5 mm) } \\
\hline $1 \mathrm{a}$ & $16.48(0.28)^{\mathrm{A}, \mathrm{a}}$ & $11.50(0.62)^{\mathrm{A}, \mathrm{b}}$ \\
\hline $1 b$ & $18.14(0.57)^{\mathrm{B}, \mathrm{a}}$ & $13.06(0.91)^{\mathrm{B}, \mathrm{b}}$ \\
\hline $1 \mathrm{c}$ & $15.02(0.54)^{\mathrm{C}, \mathrm{a}}$ & $10.01(0.69)^{\mathrm{C}, \mathrm{b}}$ \\
\hline \multicolumn{3}{|c|}{$\overline{\text { Group 2 (10 mm) }}$} \\
\hline $2 a$ & $12.40(0.20)^{\mathrm{D}, \mathrm{a}}$ & $6.76(0.59)^{\mathrm{D}, \mathrm{b}}$ \\
\hline $2 b$ & $13.62(0.62)^{\mathrm{E}, \mathrm{a}}$ & $18.51(0.62)^{\mathrm{E}, \mathrm{b}}$ \\
\hline $2 \mathrm{c}$ & $11.76(0.81)^{\mathrm{D}, \mathrm{a}}$ & $6.36(0.63)^{\mathrm{D}, \mathrm{F}, \mathrm{b}}$ \\
\hline \multicolumn{3}{|c|}{ Group $3(15 \mathrm{~mm})$} \\
\hline $3 a$ & $10.18(0.59)^{\mathrm{F}, \mathrm{a}}$ & $5.71(0.46)^{\mathrm{G}, \mathrm{b}}$ \\
\hline $3 b$ & $11.14(0.36)^{\mathrm{G}, \mathrm{a}}$ & $6.06(0.45)^{\mathrm{F}, \mathrm{G}, \mathrm{b}}$ \\
\hline $3 \mathrm{c}$ & $9.45(0.45)^{\mathrm{H,a}}$ & $5.76(0.41)^{\mathrm{G}, \mathrm{b}}$ \\
\hline
\end{tabular}

Post-hoc test: Different upper case letters within a column indicate significant differences between the groups $(P>0.05)$; Different lower case letters in a row indicate significant differences between the baseline and thermo-cycled specimens $(P>0.05)$

Adhesive Remnant Index

(ARI) scores

The adhesive remnant index scores of the specimens following debonding are presented in Table 3 . The scoring was done after visually examining both the zirconia and the bracket surface under a light stereomicroscope at $20 \times$ magnification. The ARI score was distributed to 0 and 4 among the groups. Among the baseline specimens, group 1 specimens showed more cohesive failures (scores 2 and 3), and the specimens in group 2 and group 3 showed more adhesive failures (score 0 and 1). Among the thermo-cycled specimens, the ARI scores of group 1 specimens were more or less equally distributed into adhesive (score 0 and 1) and cohesive (scores 2 and 3) failure modes. However, in group 2 and group 3 the ARI scores were largely distributed between scores 0 and 1 , implying more adhesive failures. No instance of zirconia fractures was observed in this study.
Table 3. Adhesive Remnant Index (ARI) of the groups.

\begin{tabular}{lllllllll}
\hline \multirow{2}{*}{ Groups } & \multicolumn{3}{c}{ ARI Score } \\
\cline { 2 - 9 } & \multicolumn{3}{c}{ Baseline } & \multicolumn{7}{c}{ Artificial aging } \\
\cline { 2 - 9 } & 0 & 1 & 2 & 3 & 0 & 1 & 2 & 3 \\
\hline Group 1 (5 mm) & 1 & 1 & 2 & 6 & 3 & 1 & 3 & 2 \\
1a & 2 & 1 & 2 & 5 & 2 & 1 & 5 & 2 \\
1b & 1 & 0 & 3 & 6 & 2 & 4 & 3 & 1 \\
1c & 4 & 3 & 2 & 1 & 7 & 2 & 0 & 1 \\
\hline Group 2(10 mm) & & & & & & & & \\
2a & 5 & 4 & 1 & 0 & 6 & 3 & 1 & 0 \\
2b & 5 & 3 & 1 & 1 & 7 & 2 & 1 & 0 \\
2c & 6 & 3 & 1 & 0 & 5 & 4 & 1 & 0 \\
\hline Group 3 (15 mm) & & & & & & & & \\
3a & 7 & 0 & 2 & 1 & 6 & 2 & 1 & 0 \\
3b & 8 & 1 & 1 & 0 & 6 & 2 & 1 & 1 \\
3c &
\end{tabular}

(please refer to the text for the interpretation of the ARI scores)

\section{Surface wettability and contact angle measurement}

Results of the surface wettability and water contact angle measurement of the unconditioned zirconia specimens following primer application are presented in Figure 5. The distilled water drop advanced towards the control (without primer application) zirconia specimen, failed to wet the surface and thus the water contact angle obtained was high $\left(53.5^{\circ}\right)$. However, the application of experimental primers on the zirconia surface significantly improved the wettability and the water contact angle. After primer coating, the zirconia surface showed water contact angles of $3-7^{\circ}$.

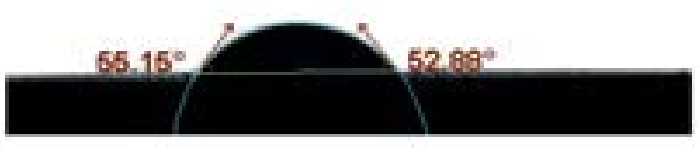

a)

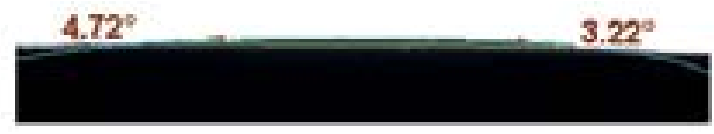

b)

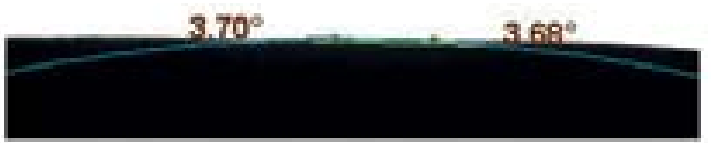

c)

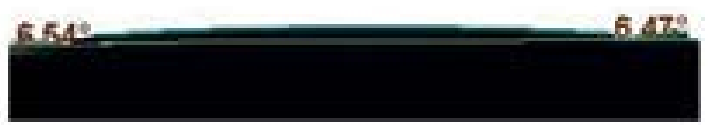

d)

Figure 5. Contact angle measurements of the zirconia specimens following primer application: a) control (no primer); b) $1.0 \% \mathrm{MPS}$; c) $1.0 \mathrm{MPS}+0.5 \% \mathrm{BTSE}$; d) $1.0 \% \mathrm{MPS}+1.0 \%$ BTSE). 


\section{DISCUSSION}

In the past decades, fixed orthodontic treatment was mainly restricted to young and adolescent patients. However, the esthetic concern of the adults in recent years have increased the demand for adult orthodontics. Orthodontic bonding to non-silica based ceramic surfaces differs significantly from bonding to silicabased ceramic surfaces. Therefore, it is of utmost importance to find ways to ensure optimal bonding of orthodontic brackets to zirconia surfaces [7]. In the current study we have evaluated the effect of an experimental adhesive silane blend system containing 3-methacryloyloxypropyltrimethoxysilane (MPS) or their blends with 1, 2-bis- (triethoxysilyl) ethane (BTSE) in achieving optimal orthodontic bonding to zirconia surfaces. Also the study was an attempt to evaluate, whether the varying grit-blasting distances could have an effect on the adhesion strength of orthodontic brackets to zirconia surfaces.

The current silane adhesive systems have been successfully applied for resin bonding to titanium and zirconia surfaces $[11,17]$. However, their use in orthodontic applications has not been reported so far. Hence we aimed at using the current silane adhesive systems to determine whether they would provide optimal ad-hesion strength of orthodontic brackets to zirconia surfaces. In clinical orthodontics, an adhesion (bond) strength of ca. $6-8 \mathrm{MPa}$ is reported to be sufficient for the treatment mechanics. In this study, all the experimental silane adhesive systems tested demonstrated optimal orthodontic bonding at baseline (dry condition).

Adhesion strength testing after orthodontic bonding and thermo-cycling is the ideal approach of measuring the adhesion strength of orthodontic brackets to various substrates. The change in temperature between the water baths $\left(5^{\circ} \mathrm{C}\right.$ and $\left.55^{\circ} \mathrm{C}\right)$ contributes to water contamination at the adhesive interface and weakens the resin [18]. Moreover, the orthodontic adhesive resin composites contains a small amount of fillers which could also contribute to the wear of the material [1]. Furthermore, previous studies have concluded that thermo-cycling has a negative effect on adhesion strength values, and this effect is quite significant [19]. Following thermocycling, the adhesion strength of the specimens decreased significantly, and the percentage decrease ranged from $30-40 \%$. This is in agreement with a previous study where the authors demonstrated that thermo-cycling weakened the adhesion strength from a mean of 18.69 to 9.53 MPa [20].

Among the experimental primer system used, the silane blend of $1.0 \mathrm{vol} \% 3$-MPS (EP1), with $0.5 \%$ BTSE (EP2) were able to provide acceptable adhesion strength values after thermo-cycling. Although EP1 demonstrated acceptable bond strength at baseline (dry) and after thermo-cycling in group 1, the same silane system failed to show acceptable adhesion strength values after thermo-cycling in group 3 . Thus, the study confirms that the addition of a cross-linking silane at low concentration $(0.5 \%)$ to form a blend with an organo-functional silane might be a promising solution in achieving acceptable adhesion strength for clinical orthodontic needs.

Previous studies have reported that silane alone does not provide optimal bonding with zirconia ceramics $[21,22]$. Grit-blasting in conjunction with silane application is the accepted protocol to enhance bonding between the resin composites and zirconia [22]. Gritblasting increases the surface roughness and improves the wettability of the material and hence increases the bond strength between the adhesive resin and the specimen [23]. However, there has been inconsistency in the previous studies regarding the distance from the gritblaster to the surface, and the distances in these studies have varied from 5 to $30 \mathrm{~mm}$ [2, 24-26].

Grit-blasting at a close distance is found to initiate heat, chipping, and cracking of the zirconia surface, thereby generating residual stresses through which strength reducing flaws are introduced [27]. On the contrary, increased distance is associated with lower surface roughness resulting in decreased or unacceptable zirconia adhesion strength $[26,27]$. In the current study, the adhesion strength varied significantly with regard to grit-blasting distance irrespective of experimental silane system used. Adhesion strength obtained in this study was $15-18 \mathrm{MPa}$ at $5 \mathrm{~mm}, 11.7-13.6 \mathrm{MPa}$ at $10 \mathrm{~mm}$ and 9.4 - $11 \mathrm{MPa}$ at $15 \mathrm{~mm}$ distance. These results correlated well with the surface roughness values (Figure 3 ) and the SEM micrographs (Figure 5). Considering the surface roughness and the impact it can have on the zirconia surface and adhesion strength, grit-blasting the zirconia surfaces from a distance of $10 \mathrm{~mm}$ was most promising.

During debonding brackets from enamel or any restorative surfaces, the clinician always expects that there is no or minimal adhesive left on the enamel or the restorative surfaces. This would convince the clinician that additional clean-up procedures to remove residual composite resin are not needed. The ARI scores after debonding (baseline) showed more cohesive (scores 2 and 3) failures for specimens grit-blasted at $5 \mathrm{~mm}$, whereas the specimens grit-blasted at $10 \mathrm{~mm}$ and $15 \mathrm{~mm}$ showed more adhesive (score 0 and 1 ) failures. The ARI scores after thermo-cycling in group 1 specimens showed an equal distribution of adhesive and cohesive failures. However, the group 2 and group 3 specimens after thermo-cycling showed adhesive (score 0 and 1) failures similar to the baseline specimens. The hydrophilic nature of the adhesive primer systems could be advantageous during clinical orthodontic bonding where complete dry environment cannot be maintained.

\section{CONCLUSION}

- Grit-blasting at various distances contributes to differences in surface roughness of zirconia specimens and to the adhesion strength of orthodontic brackets to zirconia. 
- Grit-blasting at $10 \mathrm{~mm}$ and silane primer blend of 1.0 vol. \% 3-MPS and 0.5 vol. \% BTSE provided acceptable orthodontic bonding with least surface damage to zirconia surface.

- Adhesion strength values significantly decreased following thermo-cycling, irrespective of the grit-blasting distance and the silane primer blend system used.

- The experimental silane primer blend systems were hydrophilic in nature and demonstrated enhanced wettability and water contact angles between $3^{\circ}$ and $7^{\circ}$.

Acknowledgement

The authors are grateful to the Deanship of Scientific Research, King Saud University, Riyadh, Saudi Arabia for funding this research through the Engineer Abdullah Bugshan Research Chair for Dental and Oral Rehabilitation.

\section{REFERENCES}

1. Durgesh B.H., Alhijji S., Hashem M.I., Al Kheraif A.A., Durgesh P., Elsharawy M., Vallittu P.K. (2016): Influence of tooth brushing on adhesion strength of orthodontic brackets bonded to porcelain. Biomedical Materials and Engineering, 27, 365-374. doi: 10.3233/BME-161592

2. Lee J.-H., Lee M., Kim K.-N., Hwang C.-J. (2015): Resin bonding of metal brackets to glazed zirconia with a porcelain primer. Korean Journal of Orthodontics, 45(6), 299-307. doi: 10.4041/kjod.2015.45.6.299

3. Lung C.Y.K., Matinlinna J.P. (2010): Resin Bonding to Silicatized Zirconia with Two Isocyanatosilanes and a Cross-linking Silane. Part I: Experimental. Silicon, 2(3), 153-161. doi: 10.1007/s12633-010-9044-9

4. Hannink R.H., Kelly P.M., Muddle B.C. (2000): Transformation toughening in zirconia containing ceramics. Journal of the American Ceramic Society, 83, 461-487. doi: 10.1111/j.1151-2916.2000.tb01221.x

5. Derand T., Molin M., Kvam K. (2005): Bond strength of composite luting cement to zirconia ceramic surfaces. Dental Materials, 21, 1158-1162. doi: 10.1016/j.dental. 2005.02.005

6. Jennings C.W. (1972): Surface Roughness and Bond Strength of Adhesives. The Journal of Adhesion, 4, 25-38. doi: 10.1080/00218467208072208

7. Guazzato M., Quach L., Albakry M., Swain M.V. (2005): Influence of surface and heat treatments on the flexural strength of Y-TZP dental ceramic. Journal of Dentistry, 33, 9-18. doi: 10.1016/j.jdent.2004.07.001

8. Kosmac T., Oblak C., Jevnikar P., Funduk N., Marion L. (1999): The effect of surface grinding and sandblasting on flexural strength and reliability of Y-TZP zirconia ceramic. Dental Materials, 15, 426-433. doi: 10.1016/s0109-5641 (99)00070-6

9. Matinlinna J.P., Heikkinen T., Ozcan M., Lassila L.V., Vallittu P.K. (2006): Evaluation of resin adhesion to zirconia ceramic using some organosilanes. Dental Materials, $22,824-831$
10. Scaminaci Russo D., Cinelli F., Sarti C., Giachetti L. (2019): Adhesion to Zirconia: A Systematic Review of Current Conditioning Methods and Bonding Materials. Dentistry Journal, 7, 74 doi: 10.3390/dj7030074

11. Matinlinna J.P., Lassila L.V., Vallittu P.K. (2006): The effect of three silane coupling agents and their blends with a cross-linker silane on bonding a bis-GMA resin to silicatized titanium (a novel silane system). Journal of Dentistry, 34, 740-746. doi: 10.1016/j.jdent.2006.01.008

12. Matinlinna J.P., Lassila L.V., Vallittu P.K. (2007): Pilot evaluation of resin composite cement adhesion to zirconia using a novel silane system. Acta Odontologica Scandinavica, 65, 44-51. doi: 10.1080/00016350600973060

13. Durgesh B.H., Hijji S.A., Kheraif A.A.A., Ramakrishnaiah R., Basavarajappa S., Al Sharawy M., Pekka Matinlinna J. (2015): A novel silane system as a primer for orthodontic bonding - A pilot study. International Journal of Adhesion and Adhesives, 62, 101-106.doi: 10.1016/j.ijadhadh.2015. 07.006

14. Fox N.A., McCabe J.F., Buckley J.G. (1994): A critique of bond strength testing in orthodontics. Brazilian Journal of Orthodontics, 21, 33-43. doi: 10.1179/bjo.21.1.33

15. Assery M. K., Ajwa N., Alshamrani A., Alanazi B. J., Durgesh B. H., Matinlinna J. P. (2019): Titanium dioxide nanoparticles reinforced experimental resin composite for orthodontic bonding. Materials Research Express, 6(12), 125098. doi: 10.1088/2053-1591/ab5a93

16. Artun J., Bergland S. (1984): Clinical trials with crystal growth conditioning as an alternative to acid-etch enamel pretreatment. American Journal of Orthodontics, 85, 333-340. doi: 10.1016/0002-9416(84)90190-8

17. Matinlinna J.P., Lassila L.V. (2011): Enhanced resin-composite bonding to zirconia framework after pretreatment with selected silane monomers. Dental Materials, 27, 273-280. doi: 10.1016/j.dental.2005.11.035

18. Kern M., Fechtig T., Strub J.R. (1994): Influence of water storage and thermal cycling on the fracture strength of allporcelain, resin-bonded fixed partial dentures. Journal of Prosthetic Dentistry, 71, 251-256. doi: 10.1016/0022-3913 (94)90463-4

19. Karan S., Buyukyilmaz T., Toroglu M.S. (2007): Orthodontic bonding to several ceramic surfaces: are there acceptable alternatives to conventional methods? American Journal of Orthodontics and Dentofacial Orthopedics, 132, 144.e7-144.e14. doi: 10.1016/j.ajodo.2006.12.006

20. Bourke B.M., Rock W.P. (1999): Factors affecting the shear bond strength of orthodontic brackets to porcelain. Brazilian Journal of Orthodontics, 26, 285-290. doi: 10.1093/ ortho/26.4.285.

21. Ozcan M., Vallittu P.K. (2003): Effect of surface conditioning methods on the bond strength of luting cement to ceramics. Dental Materials, 19, 725-731. doi: 10.1016/ s0109-5641(03)00019-8

22. Wegner S.M., Kern M. (2000): Long-term resin bond strength to zirconia ceramic. Journal of Adhesive Dentistry, 2, 139-147.

23. Ourahmoune R., Salvia M., Mathia T.G., Mesrati N. (2014): Surface morphology and wettability of sandblasted PEEK and its composites. Scanning, 36, 64-75. doi: 10.1002/sca. 21089

24. Chintapalli R.K., Mestra Rodriguez A., Garcia Marro F., Anglada M. (2014): Effect of sandblasting and residual stress on strength of zirconia for restorative dentistry applications. 
Journal of Mechanical Behavior of Biomedical Materials, 29, 126-137. doi: 10.1016/j.jmbbm.2013.09.004

25. Nishigawa G., Maruo Y., Irie M., Maeda N., Yoshihara K., Nagaoka N., Matsumoto T., Minagi S. (2016): Various Effects of Sandblasting of Dental Restorative Materials. PLOS ONE, 11, e0147077. doi: 10.1371/journal. pone. 0147077

26. Albakry M., Guazzato M., Swain M.V. (2004): Effect of sandblasting, grinding, polishing and glazing on the flexural strength of two pressable all-ceramic dental materials. Journal of Dentistry, 32, 91-99. doi: 10.1016/j. jdent.2003.08.006

27. Zeighami S., Gheidar, A., Mahgoli H., Rohanian A., Ghodsi S. (2017): Effect of Sandblasting Angle and Distance on Biaxial Flexural Strength of Zirconia-based Ceramics. The Journal of Contemporary Dental Practice, 18, 443-447. doi: $10.5005 /$ jp-journals-10024-2062 